\title{
Synthesis and Investigation of Phenol Red Dye Doped Polymer Films
}

\author{
Imad Al-Deen Hussein A. Al-Saidi*, Faisal Sadik \\ Department of Physics, College of Education for Pure Sciences, University of Basrah, Basrah, Iraq \\ Email: :al_saidi_imad@yahoo.com
}

Received 1 March 2016; accepted 21 May 2016; published 24 May 2016

Copyright (C) 2016 by authors and Scientific Research Publishing Inc.

This work is licensed under the Creative Commons Attribution International License (CC BY). http://creativecommons.org/licenses/by/4.0/

(c) (i) Open Access

\begin{abstract}
The optical properties of the pure polymer film and polymer films doped with Phenol Red dye at different concentrations were investigated. The films were prepared using the casting technique. Poly (methyl-methacrylate) (PMMA) polymer was doped with the Phenol Red dye dissolved in a mixture of chloroform and little quantity of methanol, used as suitable solvent for both the dye and the polymer. The spectral absorption measurements of these films were carried out at different dye concentrations using UV-Vis double-beam spectrophotometer in the wavelength range $300-800 \mathrm{~nm}$. The optical parameters of the prepared Phenol Red dye doped polymer films, absorption coefficient $(\alpha)$, extinction coefficient $(\kappa)$, refractive index $(n)$, optical and electrical conductivities ( $\sigma_{\text {opt }}$ and $\left.\sigma_{\text {elect }}\right)$, and optical energy band gap $\left(E_{g}\right)$, were determined. The results showed that the Phenol Red dye doped polymer film is a good candidate for photonic applications such as, solar cells, optical sensors, and other photonic devices.
\end{abstract}

\section{Keywords}

Optical Properties, Optical Constants, Phenol Red Dye, Dye Doped Polymer Films, Optical Energy Band Gap

\section{Introduction}

The interest in the optical properties of organic materials has grown due to the wide range of applications in photonic devices, such as sensors, light emitting diodes, solar cells, limiters, and optoelectronic devices [1]-[10]. The data obtained from the spectra of absorbance $(A)$, transmittance $(T)$, and reflectance $(R)$ of these materials can be used to determine their intrinsic parameters. These include, absorption coefficient $(\alpha)$, extinction coefficient $(\kappa)$, refractive index $(n)$, optical and electrical conductivities $\left(\sigma_{\text {opt }}\right.$ and $\left.\sigma_{\text {elect }}\right)$, and optical energy band gap

*Corresponding author. 
$\left(E_{g}\right)$. Investigation of these parameters is considerably important for the development of materials that can be used as components in the optoelectronic devices.

Organic dyes provide promising materials for photonic devices due to their excellent optical properties [10]-[14]. Phenol Red dye is one of these materials. As we find from the present study, this material has several good properties such as, high fabrication flexibility, good photo-chemical stability, high refractive index, and high dielectric constant. Poly (methyl-methacrylate) (PMMA) polymer is an important and interesting polymer can be used as host medium because of the attractive physical and optical properties decisive about its broad applications. This material has some advantages such as, good transparency in the visible region of the electromagnetic spectrum, thermal stability, and relatively high damage resistance for the laser beams [4] [15]. Introducing the Phenol red dye (as a dopant) in the PMMA will cause significant changes in their physical properties. There are various techniques, which are used to prepare solid polymer films [16] [17]. Among these techniques, casting technique is a simple and effective technique to obtain polymer films with good optical quality, as well as; it has a relatively low manufacturing cost.

In the present work, pure and Phenol Red dye doped polymer films were prepared by casting method. The optical properties of the prepared films were investigated and their useful optical parameters were determined. The effect of dye concentration on the values of these parameters was also studied.

\section{Materials and Experimental}

The molecular formula of the Phenol Red dye is $\mathrm{C}_{19} \mathrm{H}_{14} \mathrm{O}_{5} \mathrm{~S}$, and its chemical structure is shown in Figure 1. The pure and dye doped polymer films were prepared using the casting technique. Appropriate amount of poly (methyl-methacrylate) (PMMA) polymer was dissolved in a mixture of chloroform solvent and 5\% of the volume of methanol, as additive solvent. The mixture of the two solvents is suitable for both the dye and polymer. Product was stirred using a magnetic stirrer until the polymer is completely dissolved and homogeneous solution produced. Then suitable quantities of the mixture ( $2 \mathrm{ml}$ for each sample) were cast on thin glass slides and kept until the solvent gradually evaporated at room temperature and solid films obtained. The dye doped polymer films were prepared as follows: A Phenol Red dye solution with certain concentration was prepared by dissolving appropriate amount of dye powder in a mixture of chloroform and $5 \%$ of the volume of methanol. The produced solution was diluted by different ratios of the solvent in order to obtain solutions with different concentrations: $0.05,0.30,0.40 \mathrm{mM}$. Then, required amounts of PMMA polymer were added to each dye solution and the procedures for preparation of the pure polymer films were repeated. The obtained films were examined and found that they are exhibiting good optical transparency in the visible region. The thickness of the obtained films was in the range $0.85-1 \mathrm{~mm}$. For our measurements, the films with thickness $1 \mathrm{~mm}$ were used.

The Ultraviolet-Visible (UV-Vis) absorption spectra of prepared Phenol Red dye doped polymer films were characterized by using Cecil double-beam spectrophotometer (model CE-75000) with the wavelength range 190 $1100 \mathrm{~nm}$. An uncoated glass slide was used as a reference sample for the absorption measurement.

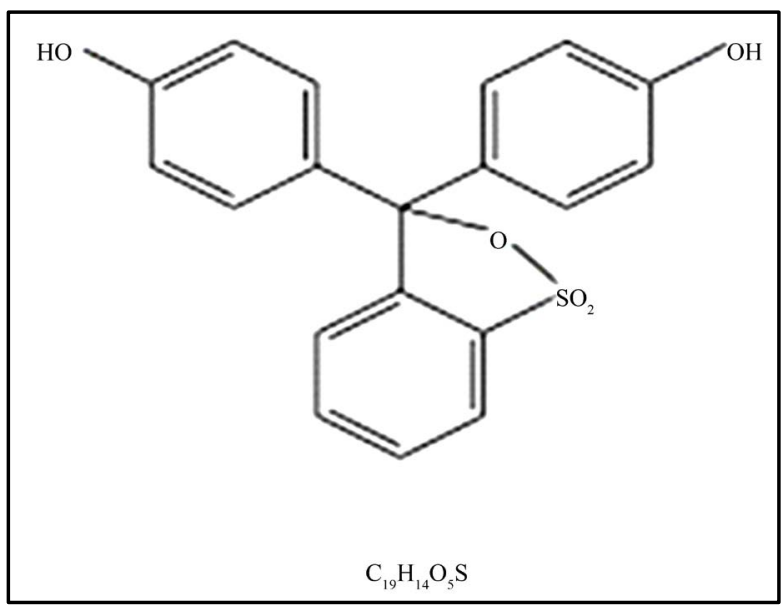

Figure 1. Chemical structure and molecular formula of Phenol Red dye. 


\section{Results and Discussion}

The spectral distributions of the absorbance (A), the transmittance $(T)$, and the reflectance $(R)$ of the Phenol Red dye doped polymer films at different concentrations were plotted as a function of the wavelength in Figures 2-4, respectively. In Figure 2, the absorbance spectra of dye doped polymer films at the concentrations $0.30 \mathrm{mM}$ and $0.40 \mathrm{mM}$ exhibited broad band centered at $418 \mathrm{~nm}$, while at the low dye concentration $0.05 \mathrm{mM}$, the absorbance spectrum does not show clear absorption peak. The transmittance reached to $80 \%$ - $90 \%$ for the Phenol Red dye doped polymer films at the low dye concentration $0.05 \mathrm{mM}$ and it decreased with increased the dye concentration, as shown in Figure 3 for the dye concentrations $0.30 \mathrm{mM}$ and $0.40 \mathrm{mM}$. It is seen from Figure 4 that the spectrum curves of the reflectance of the Phenol Red dye doped polymer films show behaviors similar to those of the absorbance; this is attributed to the correlation between reflectance and the absorbance. The value of $\mathrm{R}$ at the low dye concentration $0.05 \mathrm{mM}$ is only $5 \%$ in the visible wavelengths region and increases with increasing the dye concentration. This value reached to $21 \%$ at the dye concentration $0.40 \mathrm{mM}$; at wavelength $418 \mathrm{~nm}$. The absorbance (A) of light by an optical medium is quantified by its absorption coefficient $(\alpha)$. This is defined by the Beer-Lambert's law [18] [19]:

$$
I=I_{0} \mathrm{e}^{-\alpha L}
$$

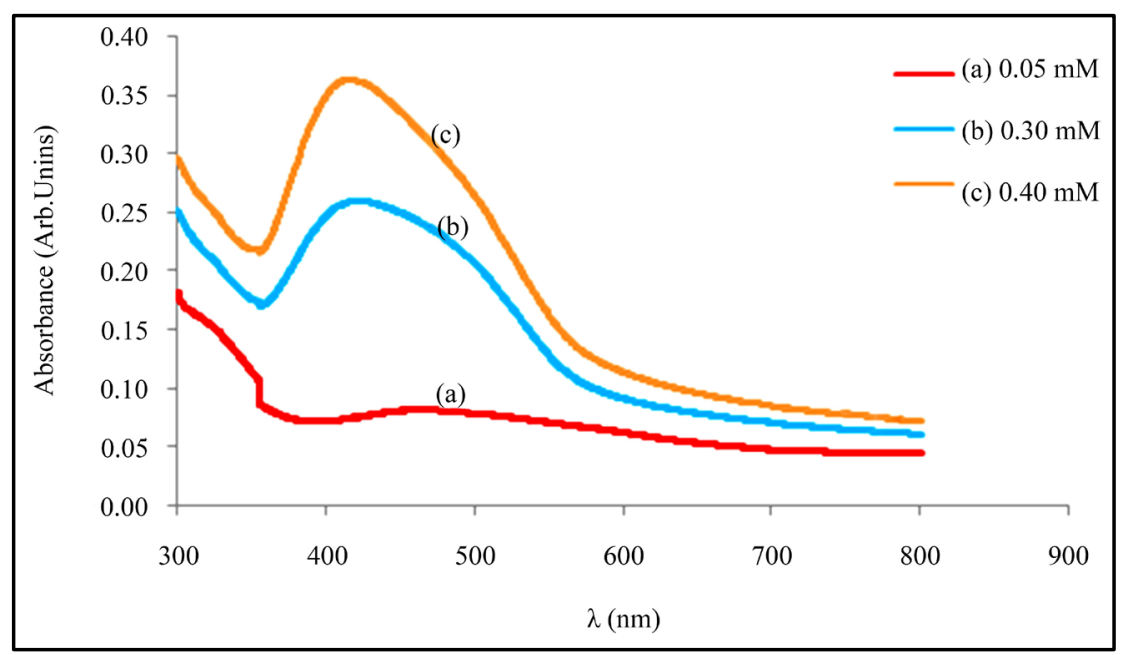

Figure 2. UV-Vis absorbance spectra of Phenol Red dye doped polymer film at different concentrations.

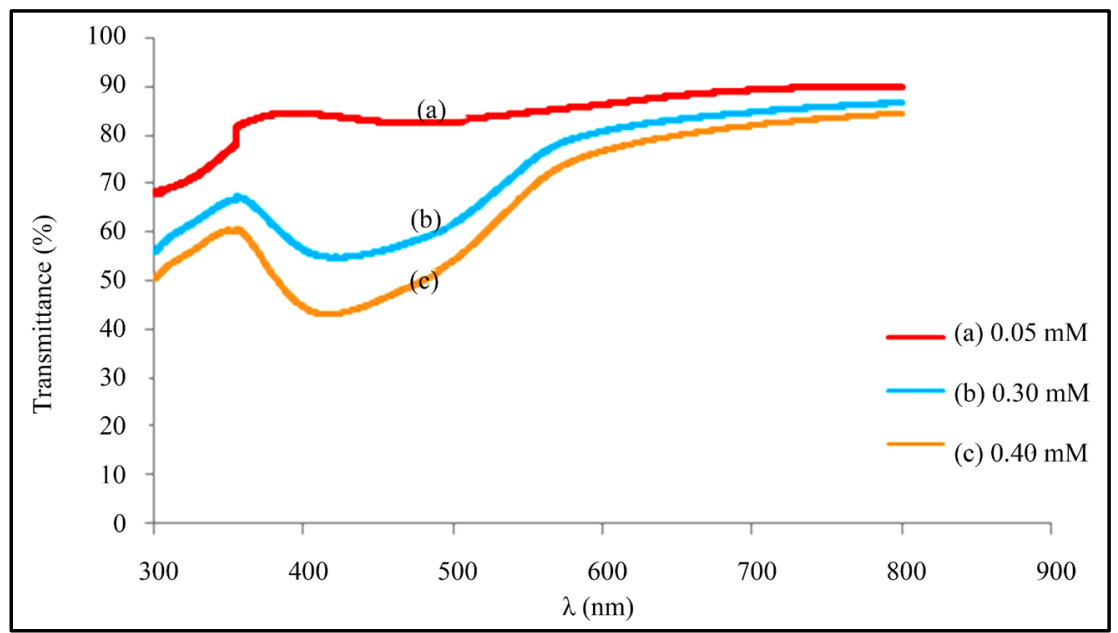

Figure 3. UV-Vis transmittance spectra of Phenol Red dye doped polymer film at different concentrations. 
where $I_{0}$ is the incident intensity of light, $I$ is the output intensity of light, and $\mathrm{L}$ is the thickness of the absorbing medium. Equation (1) can be written as follows:

$$
\alpha=2.303 \frac{A}{L}
$$

where $A=\log \left(I / I_{0}\right)$.

The values of $\alpha$ of the Phenol Red dye doped polymer films were calculated using Equation (2). The variation of $\alpha$ with the photon energy $(h v)$ at different concentrations is displayed in Figure 5. It is seen that the value of $\alpha$ increases with increasing the photon energy $(h v)$ until reached to its maximum value at incident photon energy $h v \approx 2.97 \mathrm{eV}$ and then starts to decrease with increasing $h v$. This is clearly evident with high dye concentrations. It is also seen that increasing dye concentration leads to significant increase in the value of $\alpha$. For the dye concentration range $(0.05-0.40) \mathrm{mM}$, the values of $\alpha$ vary within the range $(1.0-8.5) \mathrm{cm}^{-1}$.

Extinction coefficient $(k)$ of material is related to the absorption coefficient $(\alpha)$ according the following relation [20]:

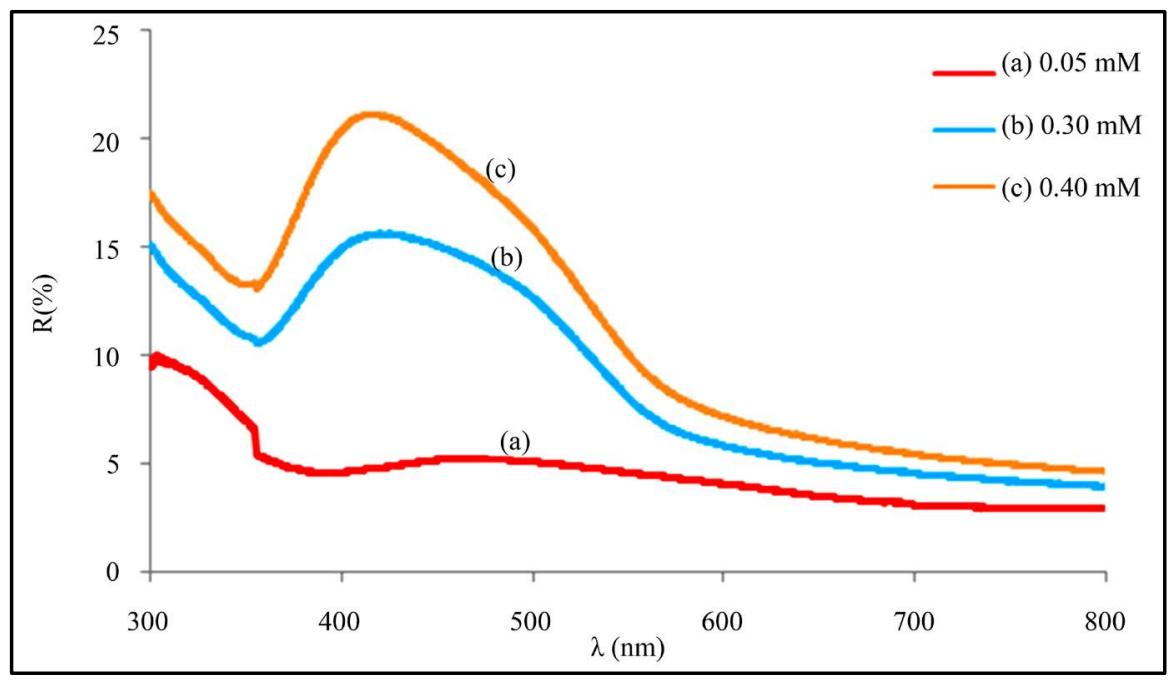

Figure 4. The reflectance $(R)$ of the Phenol Red dye doped polymer film versus the incident photon energy $(h v)$, for different dye concentrations.

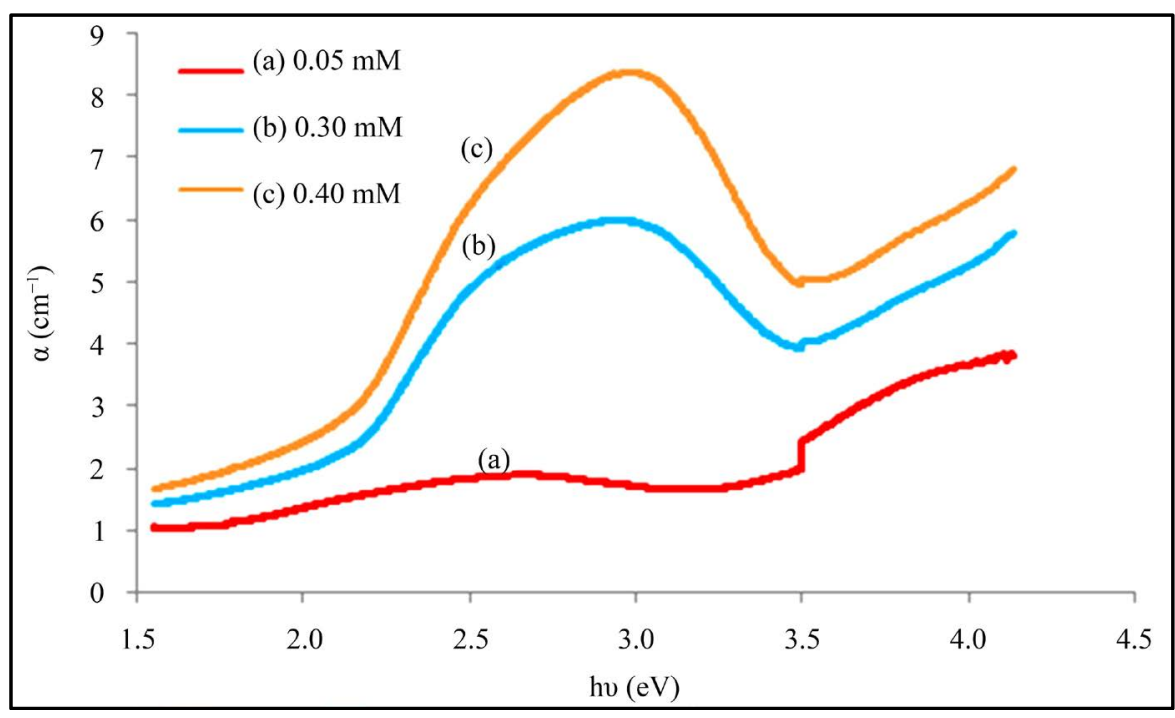

Figure 5. The absorption coefficient $(\alpha)$ of the Phenol Red dye doped polymer film versus the incident photon energy $(h v)$, for different dye concentrations. 


$$
k=\frac{\lambda \alpha}{4 \pi}
$$

where $\lambda$ is the wavelength of the incident photon.

Using the values of the corresponding $\alpha$ and Equation (3), the values of $k$ for the Phenol Red dye doped polymer films at different concentrations were calculated for different values of incident photon energy $(h v)$. The variation of $k$ of the Phenol Red dye doped polymer film with the photon energy $(h v)$ is plotted in Figure 6 for different dye concentrations. It is noticed that the variation of $k$ with $h v$ has behavior similar to that of $\alpha$ because of the direct relation between the two constants through the relation (3). The values of $k$ vary within the range (7 $29) \times 10^{-6}$ for the concentration range $(0.05-0.40) \mathrm{mM}$.

The refractive index ( $n$ ) of the Phenol red polymer film was calculated using the relation [20] [21]:

$$
n=\left[\frac{1+R}{1-R}\right]+\left[\frac{4 R}{(1-R)^{2}}-k\right]^{1 / 2}
$$

where the optical reflectance $(R)$ is given by the relation [16] [20] [21]:

$$
R=1-\left(T \mathrm{e}^{-\alpha L}\right)^{1 / 2}
$$

Figure 7 shows the variation of the refractive index $(n)$ of the Phenol Red dye doped polymer film with incident photon energy $(h v)$ for different dye concentrations. The values of $n$ are within the range $(1.40-2.50)$ for the concentration range $(0.05-0.40) \mathrm{mM}$.

The optical conductivity of the material is given by the following relation [20]:

$$
\sigma_{\text {opt }}=\frac{\alpha n c}{4 \pi}
$$

where $c$ is the velocity of light.

The electrical conductivity $\left(\sigma_{\text {elect }}\right)$ of the Phenol Red dye doped polymer film is related to its optical conductivity $\left(\sigma_{o p t}\right)$ according to the following relation [20]:

$$
\sigma_{\text {elect }}=\frac{2 \lambda \sigma_{\text {opt }}}{\alpha}
$$

We used, respectively, Equations (6) and (7) to calculate $\sigma_{\text {opt }}$ and $\sigma_{\text {elect }}$ of the Phenol Red dye doped polymer films. The variations of $\sigma_{\text {opt }}$ and $\sigma_{\text {elect }}$ with incident photon energy are shown in Figure 8 and Figure 9, respectively, for different dye concentrations. The evaluated values of $\sigma_{\text {opt }}$ are within the range $(0.40-5.00) \times 10^{10}$

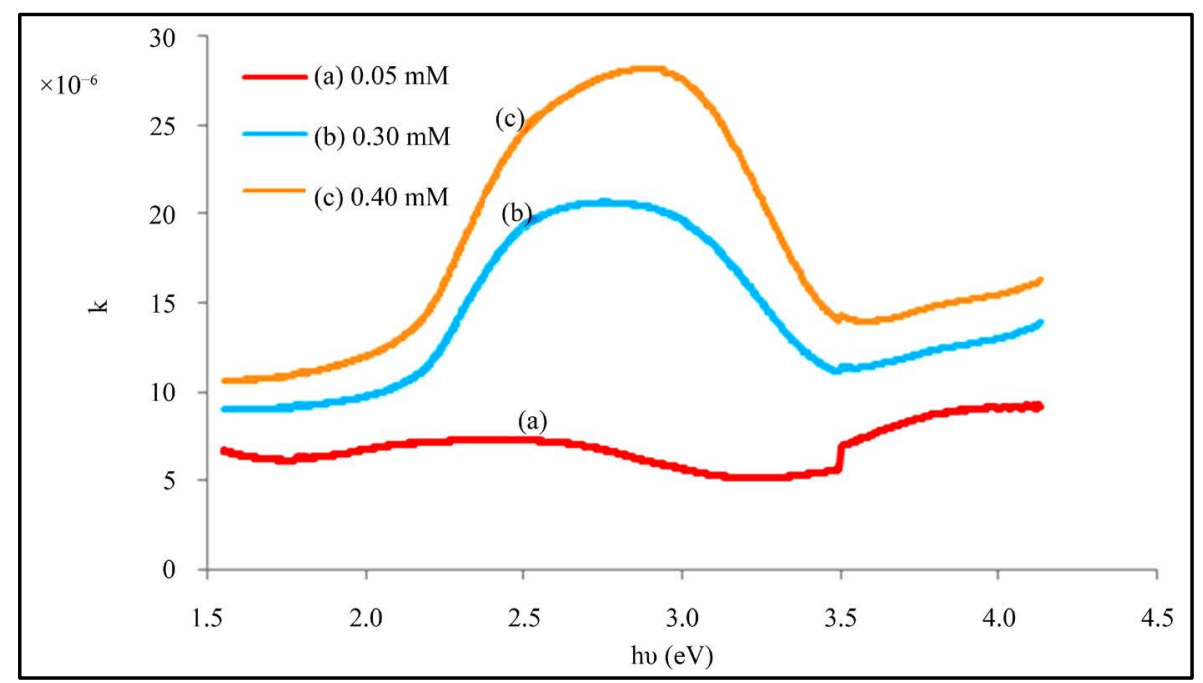

Figure 6. The extinction coefficient $(\kappa)$ of the Phenol Red dye doped polymer film versus the incident photon energy $(h v)$, for different dye concentrations. 


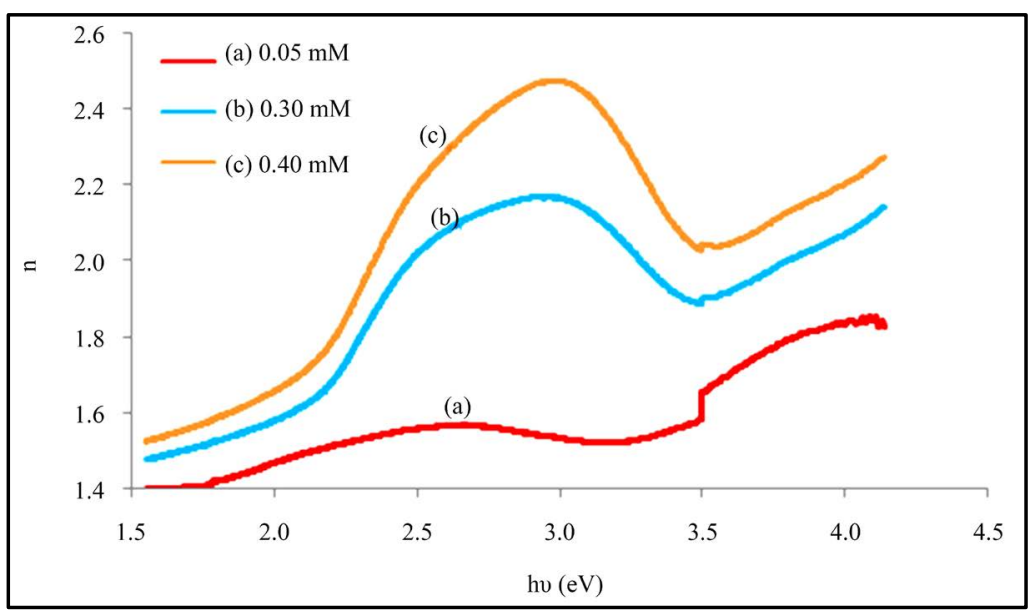

Figure 7. The refractive index ( $n$ ) of the Phenol Red dye doped polymer film versus the incident photon energy $(h v)$, for different dye concentrations.

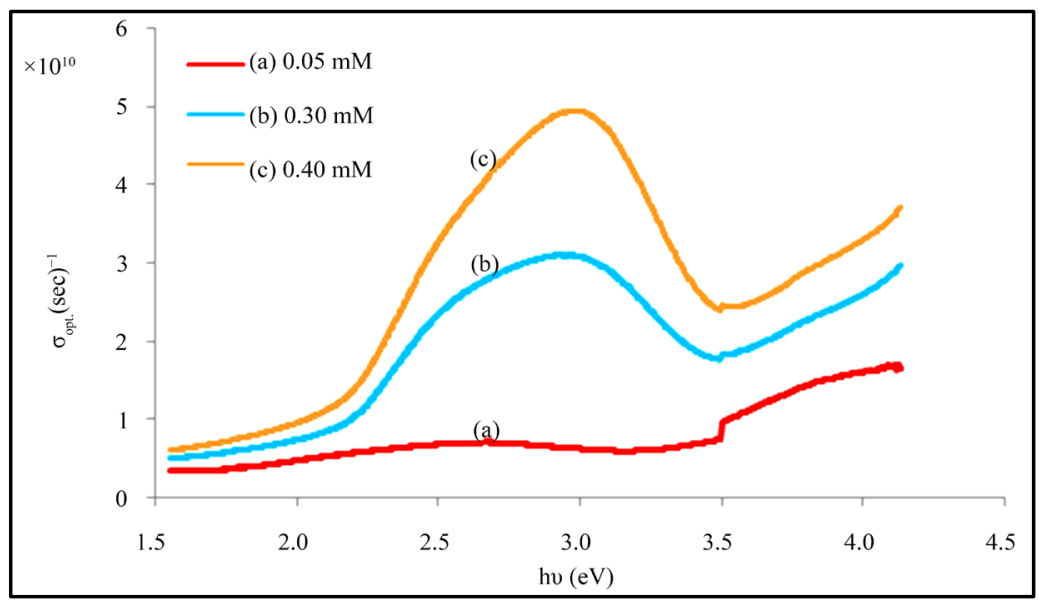

Figure 8 . The variation of the optical conductivity $\left(\sigma_{\text {opt }}\right)$ with the incident photon energy $(h v)$ for the Phenol Red dye doped polymer films at concentrations 0.05 , 0.30 , and $0.40 \mathrm{mM}$.

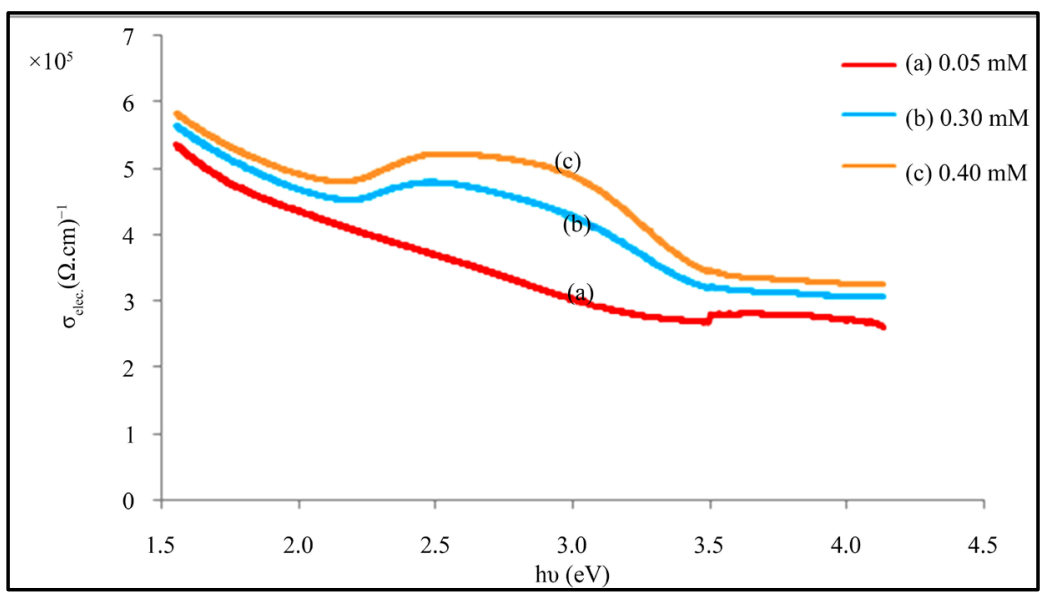

Figure 9. The variation of the electrical conductivity $\left(\sigma_{\text {elect }}\right)$ with the incident photon energy $(h v)$ for the Phenol Red dye doped polymer films at concentrations $0.05,0.30$, and $0.40 \mathrm{mM}$. 
$(\mathrm{sec})^{-1}$, while the values of $\sigma_{\text {elect }}$ are within the range $(3-6)(\Omega \cdot \mathrm{cm})^{-1}$, over the dye concentration range (0.05 $0.40) \mathrm{mM}$. It is seen that the value of $\sigma_{\text {elect }}$ is high at the low photon energies and decreases with increasing $h v$.

The optical energy band gap $\left(E_{g}\right)$ of the film is related to its absorption coefficient $(\alpha)$ and the energy of the incident photon $(h v)$ according to the following relation [18] [21] [22]:

$$
(\alpha h v)^{m}=B\left(h v-E_{g}\right)
$$

where $h$ is the Planck's constant, $v$ is the frequency of incident radiation, $B$ and $m$ are constants. The value of $m$ is dependent on the type of transition between the valence band and the conduction band of the material. $\mathrm{m}$ takes the values: $2,3,1 / 2$, or $3 / 2$, for allowed direct, forbidden direct, allowed indirect, or forbidden indirect, transitions, respectively. In the present work, the analysis of UV-V is absorption spectra revealed that the dye doped polymer films, have allowed indirect transitions, therefore the value of $m=1 / 2$ was used in Equation (8) for the $E_{g}$ determination. The values of $E_{g}$ of the pure and the Phenol Red dye doped polymer films, with the dye concentrations $0.05,0.30$, and $0.40 \mathrm{mM}$, were obtained from extrapolating the straight-line portions of the curves $(\alpha h v)^{1 / 2}$ versus hv to the $h v$-axis (where $\alpha h v=0$ ), as shown in Figure 10. For clarity, the three graphs were plotted separately in Figure 10. The obtained values of $E_{g}$ are summarized in Table 1 . The $E_{g}$ value of the pure PMMA polymer film was determined to be $4.73 \mathrm{eV}$. This value is comparable to the value reported by other workers [23] [24]. It was observed that the addition of Phenol Red dye at different concentrations in PMMA polymer changed the value of $E_{g}$. The value of $E_{g}$ decreased with increased the doping concentration. The values
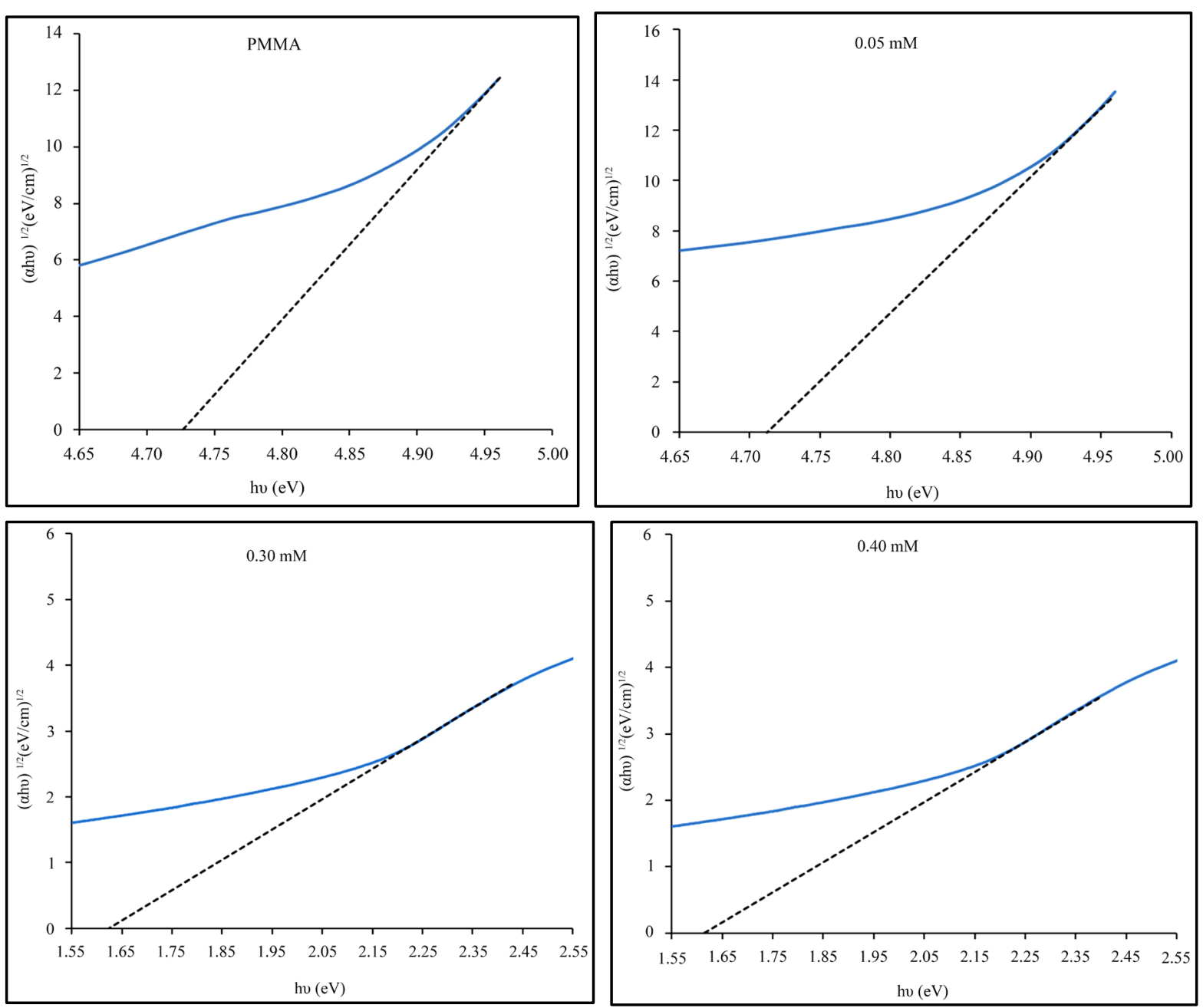

Figure 10. The plots of $(\alpha h v)^{1 / 2}$ versus $h v$ for Pure PMMA polymer film and Phenol Red dye doped polymer films at concentrations $0.05,0.30$, and $0.40 \mathrm{mM}$. 
Table 1. The obtained values of optical band gap energy $\left(E_{q}\right)$ for the pure PMMA polymer film and the Phenol Red dye doped polymer films at different concentrations.

\begin{tabular}{cc}
\hline Sample & Optical energy band gap $\left(E_{g}\right)(\mathrm{eV})$ \\
\hline PMMA & 4.73 \\
PR $0.05 \mathrm{mM}$ & 4.71 \\
PR $0.30 \mathrm{mM}$ & 1.63 \\
PR $0.40 \mathrm{mM}$ & 1.61 \\
\hline
\end{tabular}

of $E_{g}$ for the dye doped polymer films were found to be in the range of (4.71 - 1.61) eV, when the dye concentration increased over the range $(0.05-0.40) \mathrm{mM}$. The decrease in the value of $E_{g}$ might be due to the formation of defects in the polymer matrix, which results in creation of localized sublevels in the optical band gap and consequently decreased the energy band gap.

\section{Conclusion}

The pure and Phenol Red dye doped polymer films were synthesized using the casting technique and their optical properties were investigated for different dye concentrations. The main optical parameters of the dye doped polymer films were determined for different dye concentrations. Results showed that the optical properties of the PMMA polymer film were appreciably modified in the presence of the organic Phenol Red dye. The optical energy band gap $\left(E_{g}\right)$ values of the prepared polymer films show the decreasing trend with an increasing concentration of Phenol red dye. The obtained results from the investigation suggest that the prepared Phenol Red dye doped polymer films are useful for potential applications in solar cells, as well as in optoelectronic and photonic devices.

\section{References}

[1] Harsanyi, G. (1995) Polymer Films in Sensor Applications: Technology, Materials, Devices and Their Applications. Technomic Publishing Company Inc., Lancaster, PA.

[2] Kim, D.Y., Cho, H.N. and Kim, C.Y. (2000) Blue Light Emitting Polymers. Progress in Polymer Science, 25, 10891139.

[3] Grazulevicius, J. V., Strohriegl, P. and Pielichowski, J. (2003) Carbazole-Containing Polymers: Synthesis, Properties and Applications. Progress in Polymer Science, 28, 1297-1353. http://dx.doi.org/10.1016/S0079-6700(03)00036-4

[4] Yeh, S.-L., Zhu, C.-Y. and Kuo, S.-W. (2015) Transparent Heat-Resistant PMMA Copolymers for Pacing Light-Emitting Diode Materials, Polymers, 7, 1379-1388. http://dx.doi.org/10.3390/polym7081379

[5] Lo, S.-C. and Burn, P.L. (2007) Development of Dendrimers: Macromolecules for Use in Organic Light-Emitting Diode and Solar Cells. Chemical Reviews, 107, 1097-1116.

[6] Seo, K.D., et al. (2011) Coumarin Dyes Containing Low-Band-Gap Chromophores for Dye-Sensitised Solar Cells. Dyes and Pigments, 90, 304-310. http://dx.doi.org/10.1016/j.dyepig.2011.01.009

[7] Sacco, A., et al. (2016) Dye-Sensitized Solar Cell for a Solar Concentrator System. Solar Energy, 125, 307-313. http://dx.doi.org/10.1016/j.solener.2015.11.026

[8] Al-Saidi, I. Al-D.H. and Abdulkareem, S. Al-D. (2015) Nonlinear Optical Properties and Optical Power Limiting of Leishman Dye Using Z-Scan Technique. Journal of Materials Science: Materials in Electronics, 26, 2713-2718. http://dx.doi.org/10.1007/s10854-015-2747-3

[9] Nalwa, H.S. (Ed.) (2001) Handbook of Advanced Electronic and Photonic Materials and Devices. Academic Press, New York.

[10] Guo, Y., Kao, C.K., Li, E.H. and Chang, K.S. (2002) Nonlinear Photonics: Nonlinearities in Optics, Optoelectronics and Fiber Communications. The Chinese University Press and Springer-Verlag, Berlin.

[11] Kobayashi, T. (Ed.) (1989) Nonlinear Optics of Organics and Semiconductors, Springer Proceedings in Physics, Vol. 36. Springer-Verlag, Berlin. http://dx.doi.org/10.1007/978-3-642-93426-1

[12] Günter, P. (Ed.) (2000) Nonlinear Optical Effects and Materials. Springer-Verlag, Berlin. http://dx.doi.org/10.1007/978-3-540-49713-4 
[13] Zollinger, H. (2003) Color Chemistry: Synthesis, Properties and Applications of Organic Dyes and Pigments. 3rd Edition, Wiley-VCH, Cambridge.

[14] Ostroverkhova, O. (Ed.) (2013) Handbook of Organic Materials for Optical and Opto-electronic Devices: Properties and Applications. Woodhead Publishing Ltd., Cambridge, UK. http://dx.doi.org/10.1533/9780857098764

[15] Costela, A., et al. (2001) Laser Performance of Pyrromethene 567 Dye in Solid Polymeric Matrices with Different Cross-Linking Degrees. Journal of Applied Physics, 90, 3159-3166. http://dx.doi.org/10.1063/1.1398598

[16] Eckertova, I. (1986) Physics of Thin Films. 2nd Edition, Plenum Press, New York.

[17] Frey, H. and Khan, H.R. (Eds.) (2015) Handbook of Thin Film Technology. Springer-Verlag, Berlin. http://dx.doi.org/10.1007/978-3-642-05430-3

[18] Mott, N.F. and Davis, A.E. (1979) Electronic Process in Non-Crystalline Materials. 2nd Edition, University Press, Oxford.

[19] Gray, D.E. (Ed.) (1982) American Institute of Physics Handbook. 3rd Edition, McGrow Hill Book Co., New York.

[20] Pankove, J.I. (1971) Optical Processes in Semiconductors. Prentice Hall, New York.

[21] Moss, T.S. (1974) Optical Properties of Semiconductors. Academic Press, New York.

[22] Tauc, J. (1974) Amorphous and Liquid Semiconductors, Vol. 159. Plenum Press, New York. http://dx.doi.org/10.1007/978-1-4615-8705-7

[23] S`vorcik, V., Lyutakov, O. and Huttel, I. (2008) Thickness Dependence of Refractive Index and Optical Gap of PMMA Layers Prepared Under Electrical Field. Journal of Materials Science: Materials in Electronics, 19, 363-367. http://dx.doi.org/10.1007/s10854-007-9344-Z

[24] Dorranian, D., Golian, Y. and Hojabr, A. (2012) Investigation of Nitrogen Plasma Effect on the Nonlinear Optical Properties of PMMA. Journal of Theoretical and Applied Physics, 6, 1-8. http://dx.doi.org/10.1186/2251-7235-6-1 